\title{
Operational Design of the Ferry Transportation System based on Simulation
}

\author{
by Suprayogi*, Student Member Hiroyuki Yamato**, Member
}

\begin{abstract}
Summary
This paper addresses on the development of a simulation model of a ferry transportation system. The system under study is Merak-Bakauheni ferry route, one of ferry routes in Indonesia. This route links Java and Sumatra islands. Merak is located in the western of Java and Bakauheni in the southern of Sumatra. This route crosses the Sunda Street and has a distance of fifteen miles. There are two kinds of ships - high-speed and ro-ro ships - serving this route. The focus of this study is the ferry system of ro-ro ships that are used to carry both passengers and various kinds of cars. The main inputs of the simulation model consists of a timetable, patterns of passenger and car arrivals, and ship capacities. In addition to initial experiment, two other types of experiments are carried out. The first is performed to determine a better timetable. The alternative timetables are generated and each is evaluated in terms of waiting times. The second one is carried out to determine the most suitable ship type (passenger and car capacities). By using the simulation model, each ship type is evaluated based on its total cost consisting of waiting time cost and ship running cost. The simulation model is developed by using a commercial simulation software, ProModel.
\end{abstract}

\section{Introduction}

This paper addresses on the development of a simulation model for the ferry transportation system. The case study is Merak-Bakauheni ferry route, one of ferry routes in Indonesia. This route links Java and Sumatra islands. Merak is located in the western of Java and Bakauheni in the southern of Sumatera. This route crosses the Sunda Strait and has a distance of 15 miles. There are two kinds of ships high-speed and ro-ro ships - serving this route. The focus of this study is the development of the simulation model for the ro-ro ship operation used to

* Graduate School of Engineering, The University of Tokyo

** Graduate School of Frontier Sciences, The University of Tokyo

Received 10 th Jan. 2001

Read at the Spring meeting 17, 18 th May 2001 carry both passengers and various kinds of cars. In this model, there are three types of cars considered, i.e. small cars, buses, and trucks.

Some studies related with the simulation models has been carried out by several authors. One of them was studied by Tarigan (1992) ${ }^{1}$. He applied a simple simulation to evaluate the operational system.

This paper is further development of the previous work conducted by the author ${ }^{2}$. In the previous work, the author developed a prototype model. At present, authors include realistic data especially for arrival data. In this paper, authors conduct some experiments by changing input elements of the model. In addition to the initial experiment, two other experiments are performed. The first experiment involves changing timetable and is performed to determine a better one. The second experiment is carried by changing ship types (passenger and car capacities) and is used to determine the most suitable ship type. 


\section{Description of the Ferry Transportation System}

Merak-Bakauheni ferry route is one of ferry routes in Indonesia that links Java and Sumatra islands (Fig. 1). This route was opened in the mid 1981. In 1997, number of passengers transported in this route reached 13.34 million people and number of cars was 1.85 million units ${ }^{3)}$. The traffic volumes fluctuate greatly throughout the year. The highest peak appears in "Lebaran" (end-of-Ramadan) season and school vacation.

Using a sample of October 1998, average daily traffic volumes for ro-ro ships are shown in Fig. 2. These figures illustrate average patterns of traffic volumes per day in the week for both passengers and cars (small cars, buses, and trucks).

Estimated hourly arrival patterns for passengers and cars are shown in Fig. 3. These figures are derived from data of passengers and cars loaded in several days in October 1998. These figures illustrates peak arrival periods. The peak arrival of passengers, for example, occurs around at noon in both Merak and Bakauheni.

Table 1 lists twenty ships operated during JulyDecember $1998^{4}$. In terms of capacities, these ships

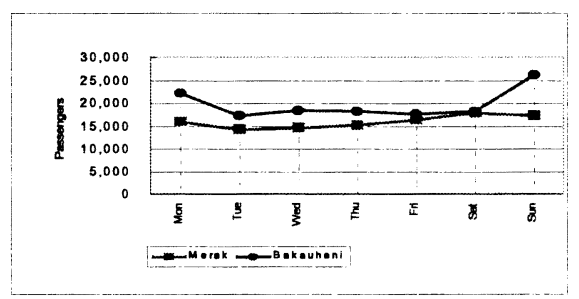

(a) passengers

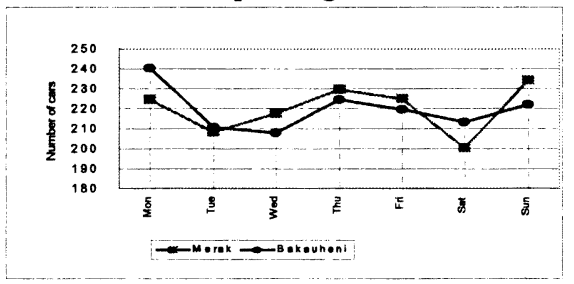

(c) buses have different sizes. The passenger capacity varies between the minimum of 379 passengers and the maximum of 1,300 passengers. The car capacity differs from 45 cars until 175 cars.

In 1998 there are three berths available in each ferry port. One berth has a maximum capacity of 3,000 GRT and two other berths have a maximum capacity of 5,000 GRT. From each side, number of trips varies between 50 and 55 trips per day with interdeparture intervals of 20 or 30 minutes. The trip time of each ship is three hours consisting of sailing time and berthing time. Table 2 shows a part of timetable list ${ }^{5}$. This list tells about departure times, ships names, and origin and destination berths of each port.

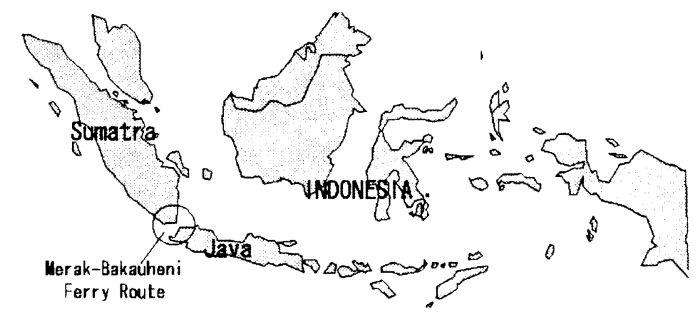

Fig.1 Location of Merak-Bakauheni ferry route

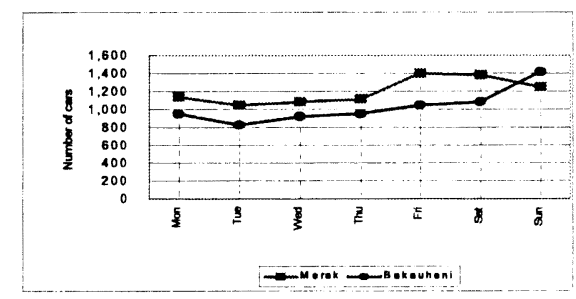

(b) small cars

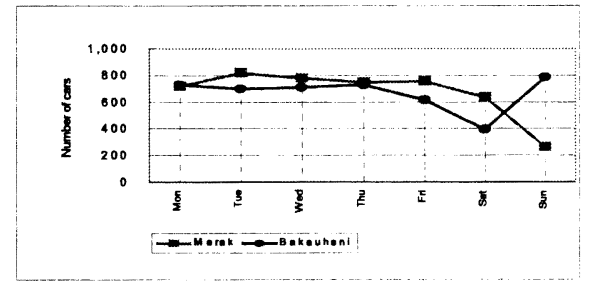

(d) trucks

Fig.2 Daily traffic volumes 


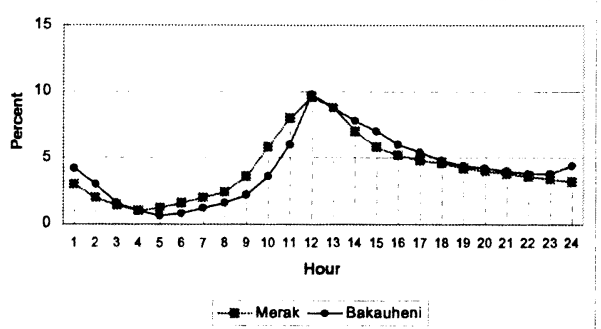

(a) passengers

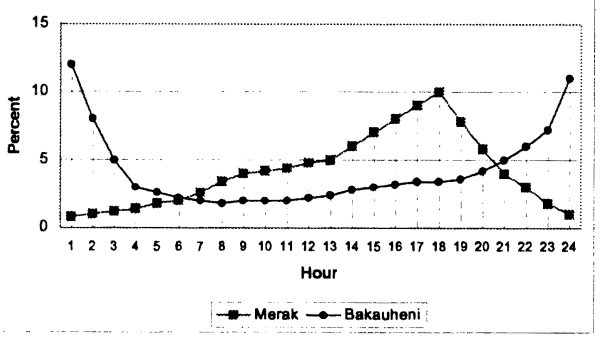

(c) buses

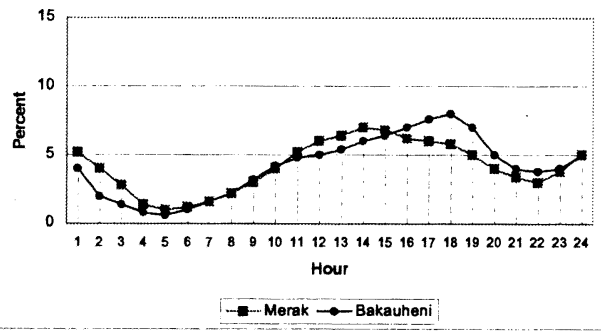

(b) small cars

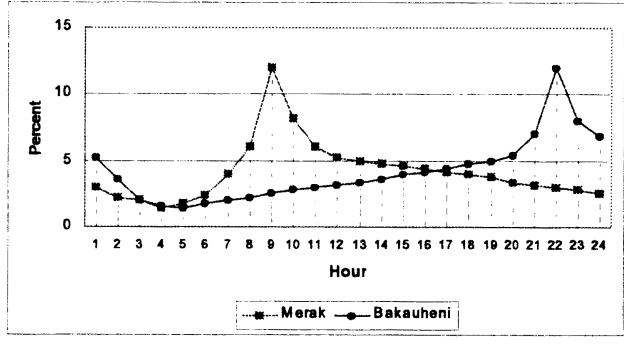

(d) trucks

Fig.3 Estimated hourly arrival patterns

Table 1 Ro-ro ship data

\begin{tabular}{|c|c|c|c|c|c|c|c|c|}
\hline No. & Name & $\begin{array}{l}\text { Length } \\
\text { (m) }\end{array}$ & $\begin{array}{c}\text { Breadth } \\
\text { (m) }\end{array}$ & $\begin{array}{c}\text { Draught } \\
\text { (m) }\end{array}$ & $\begin{array}{c}\text { GRT } \\
\text { (tons) }\end{array}$ & $\begin{array}{l}\text { Speed } \\
\text { (knot) }\end{array}$ & $\begin{array}{l}\text { Passenger } \\
\text { capacity }\end{array}$ & $\begin{array}{c}\text { Car } \\
\text { capacity })\end{array}$ \\
\hline 1. & JATRA I & 90.79 & 15.60 & 4.00 & 3,932 & 14 & 1,000 & 47 \\
\hline 2. & JATRA II & 90.79 & 15.60 & 4.00 & 3,932 & 14 & 1,000 & 47 \\
\hline 3. & LAMPUNG & 94.25 & 16.00 & 5.00 & 4,841 & 17 & 425 & 110 \\
\hline 4. & MENGGALA & 93.44 & 17.00 & 5.55 & 4,841 & 13 & 898 & 100 \\
\hline 5. & MUFIDAH & 93.50 & 18.00 & 4.29 & 4,330 & 20 & 697 & 70 \\
\hline 6. & NUSA DHARMA & 104.34 & 15.02 & 3.52 & 5,584 & 15 & 614 & 60 \\
\hline 7. & NUSA JAYA & 101.50 & 18.03 & 4.50 & 3,282 & 15 & 768 & 150 \\
\hline 8. & NUSA BAHAGIA & 98.53 & 15.70 & 3.25 & 4,564 & 15 & 400 & 75 \\
\hline 9. & NUSA MULIA & 114.75 & 17.40 & 10.80 & 3,555 & 16 & 500 & 90 \\
\hline 10. & NUSA SETIA & 111.88 & 16.00 & 5.98 & 6,095 & 15 & 550 & 70 \\
\hline 11. & WINDU KARSAP. & 50.83 & 16.22 & 3.21 & 1,376 & 16 & 379 & 45 \\
\hline 12. & H.M. BARUNAI & 90.60 & 17.60 & 5.00 & 4,535 & 17 & 980 & 80 \\
\hline 13. & RAJABASA & 91.50 & 17.50 & 5.00 & 4,764 & 17 & 869 & 74 \\
\hline 14. & TITIAN MURNI & 93.50 & 15.80 & 4.45 & 3,614 & 14 & 887 & 65 \\
\hline 15 & CITRA BAHARI & N/A & N/A & N/A & $\mathrm{N} / \mathrm{A}$ & N/A & 1,150 & 65 \\
\hline 16. & JATRA I BSP & 97.39 & 18.00 & 5.80 & 5,057 & 20 & 935 & 90 \\
\hline 17. & ONTOSENO I BSP II & 100.00 & 20.40 & 4.65 & 5,227 & 13 & 572 & 125 \\
\hline 18. & TRIBUANAI & 107.00 & 21.00 & 4.57 & 6,186 & 17 & 400 & 175 \\
\hline 19. & ADINDA LESTARI 101 & 111.60 & 17.07 & 5.00 & 6,398 & 19 & 1,300 & 50 \\
\hline 20. & ADINDA LESTARI 102 & 105.50 & 17.00 & 3.60 & 4,873 & 16 & 1,300 & 50 \\
\hline
\end{tabular}

") in mixed car unit 
Table 2 A part of timetable list

\begin{tabular}{|c|c|c|c|c|c|c|}
\hline \multirow[t]{2}{*}{ No } & \multirow[t]{2}{*}{ Clock } & \multicolumn{2}{|c|}{ From Merak } & \multirow[t]{2}{*}{ Clock } & \multicolumn{2}{|c|}{ From Bakauheni } \\
\hline & & Vessel Name & Berth & & Vessel Name & Berth \\
\hline 1 & $00: 30$ & TITIAN MURNI & 1 & $00: 30$ & NUSA MULIA & II \\
\hline 2 & $01: 00$ & HM. BARUNA & II & 01:00 & ONTOSENO & 1 \\
\hline 3 & $01: 20$ & ADINDA LESTARI 101 & IV & $01: 20$ & & \\
\hline 4 & $01: 40$ & LAMPUNG & 1 & $01: 40$ & JATRA IBSP & $\|$ \\
\hline 5 & $02: 00$ & RAJABASA & II & $02: 00$ & MENGGALA & 1 \\
\hline 6 & $02: 30$ & NUSA BAHAGIA & 1 & $02: 30$ & TRIBUANA & II \\
\hline . & . & & . & . & & . \\
\hline 51 & $22: 00$ & CITRA BAHARI & II & $22: 00$ & HM. BARUNA & 1 \\
\hline 52 & $22: 20$ & ADINDA LESTARI 102 & IV & $22: 20$ & & \\
\hline 53 & $22: 40$ & JATRA I BSP & 1 & $22: 40$ & MUFIDAH & $\|$ \\
\hline 54 & $23: 00$ & MENGGALA & II & $23: 00$ & RAJABASA & 1 \\
\hline 55 & $23: 30$ & TRIBUANA & $T$ & $23: 30$ & NUSA BAHAGIA & II \\
\hline 56 & $24: 00$ & WINDU KARSA & II & $24: 00$ & JATRA II & 1 \\
\hline
\end{tabular}

\section{Simulation Model}

To make a simulation model for the ferry transportation systems, the following inputs are required: timetable information, ship information, nature of customers, port conditions, and route characteristics. Timetable consists of information such as departure times of each trip and ship name for that trip. Ship information includes data such as passenger and car capacities. Nature of passengers and cars contains information like hourly and daily arrival patterns. The performance measure of the ferry transportation system is the total cost including waiting costs of passengers and cars, and ship running cost. Fig. 4 illustrates the concept of the simulation model.

The simulation model is developed using a commercial simulation software, ProModel. Elements of the model representation in terms of ProModel terminology can be stated as follows.

Passengers, cars, and trips

Passengers, cars, and trips are modeled as entities and must be treated as different entities based on their origins (i.e. Merak and Bakauheni). Before arriving in terminal, cars are treated as individual types, such as small cars, buses, and trucks.

\section{Queues}

Passengers and cars waiting for ships are modeled as entities in queue. First-in first-out (FIFO) queuing rule is applied.

\section{Arrivals}

Passengers and cars arrive at a terminal are treated separately by day. Arrival times of trips are determined by their departure times in the timetable lists. When a trip arrives, information such as ship name, its passenger and car capacities, and berth origins are generated.

\section{Processing}

Processing of passengers and cars begins with their arrivals in the terminal. Passengers and cars are joined together with trips. Number of passengers and cars loaded into a ship is determined by the ship's capacity and the number of passengers and cars waiting in the terminal. Trips are routed according to their berth origin and destination. Trips leave the system after they arrive at their destination. Fig 5 shows the basic flow of the entities in the system modeled.

The main part of the simulation model is to determine number of passengers and cars that can be loaded into each ship. Number of passengers loaded (NPL) can be determined using the following formulation:

$$
N P L=\min \{N P T, P C\}
$$

where NPT is number of passengers in terminal, and $P C$ is ship's passenger capacity. In the same manner, number of cars loaded $(N C L)$ is determined 
by the minimum value between number of cars in terminal (NCT) and car capacity $(C C)$ as given in the following formulation:

$$
N C L=\min \{N C T, C C\}
$$

In case of cars, all numbers are represented in small car unit. The size of buses and trucks is assumed as twice than small cars. Therefore, number of cars in terminals is determined using the following formulation:

$$
N C T=N S C+2(N B+N T)
$$

where NSC, NB, and NT are number of small cars, buses, and trucks, respectively.

Passengers and cars (small cars, buses, trucks) are generated using daily and hourly arrival patterns. Trips are generated using the timetable lists. Trips convey information such as ship names including their passenger and car capacities. The diagram of the main part of the simulation model is shown in Fig. 6.

Two typical screen-displays during the simulation are given in Fig. 7. Fig. 7(a ) shows ship movements during the simulation. Fig. 7(b) displays the status of each trip. In this display, information about ships and number of passengers and cars are provided.

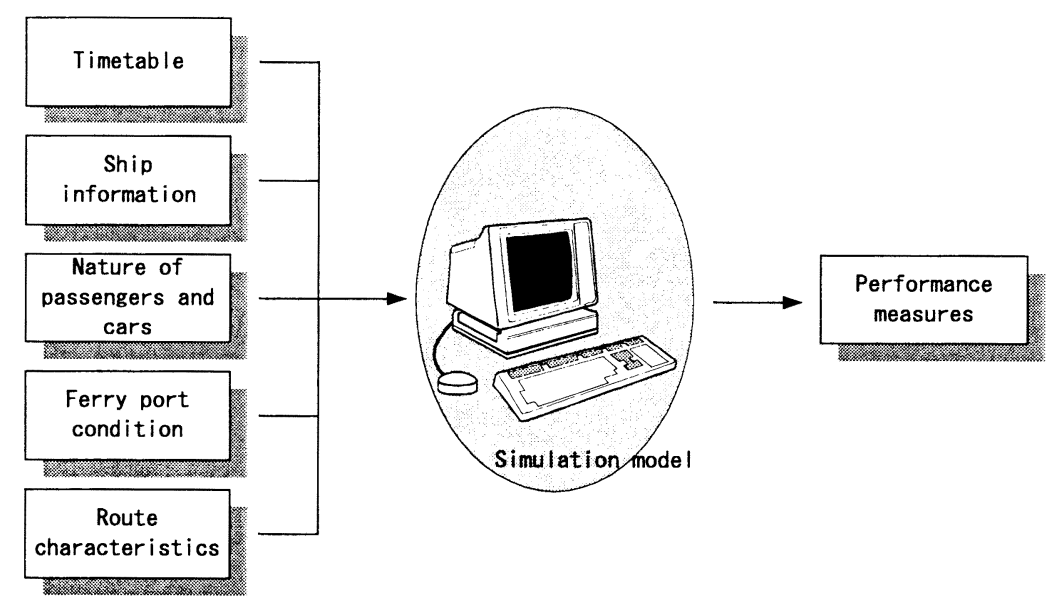

Fig.4 Concept of the simulation model

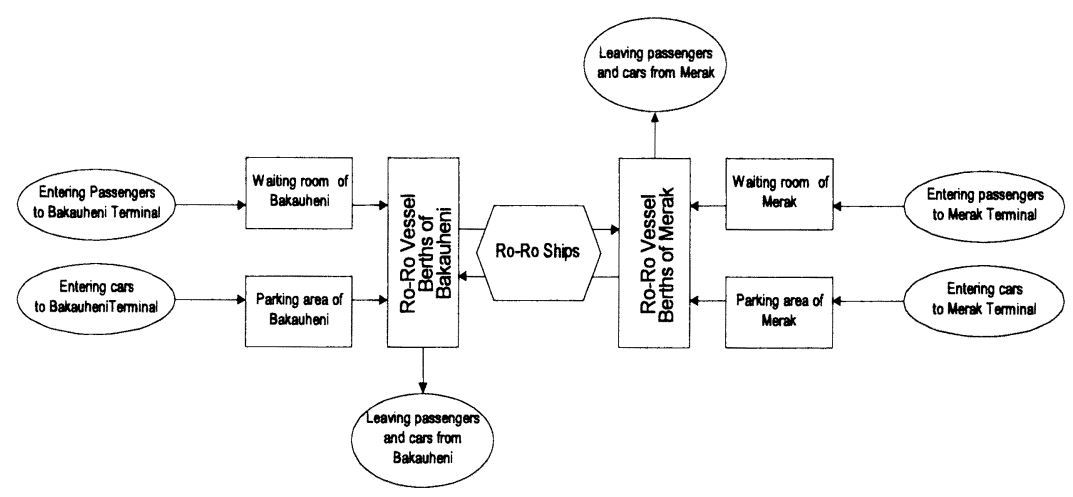

Fig.5 Basic flow of the entities 


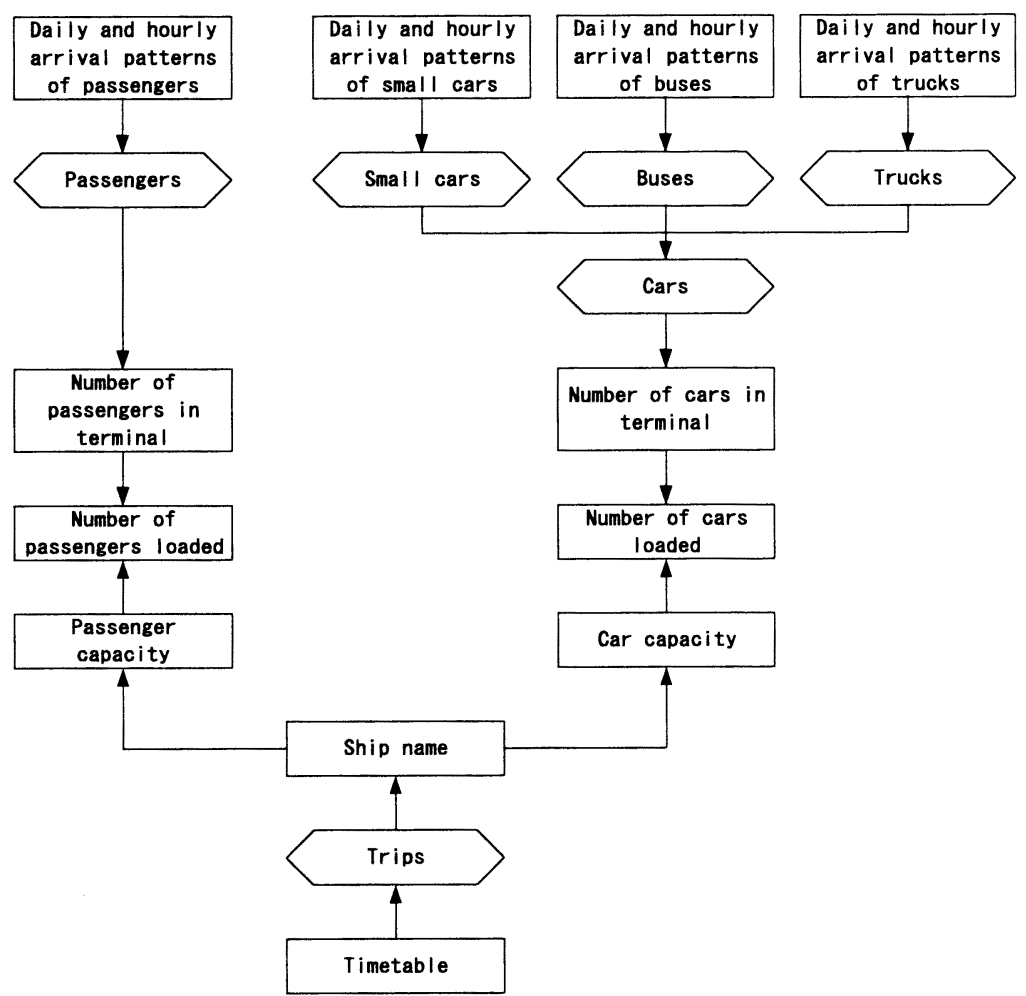

Fig.6 Diagram of the main part of the simulation model

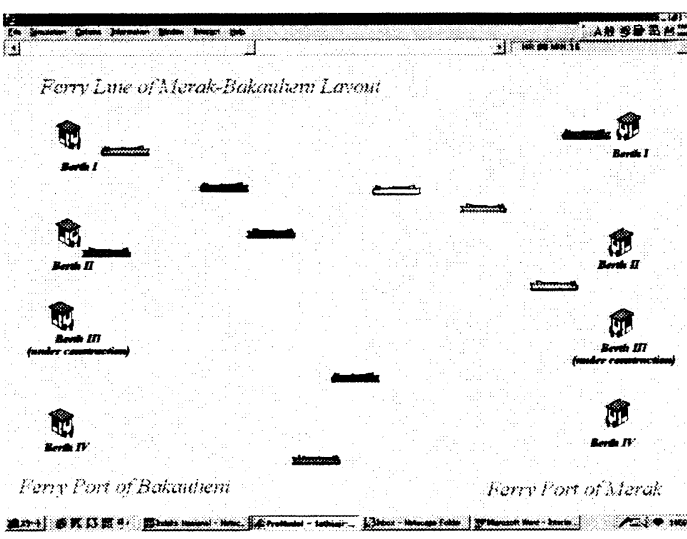

(a)

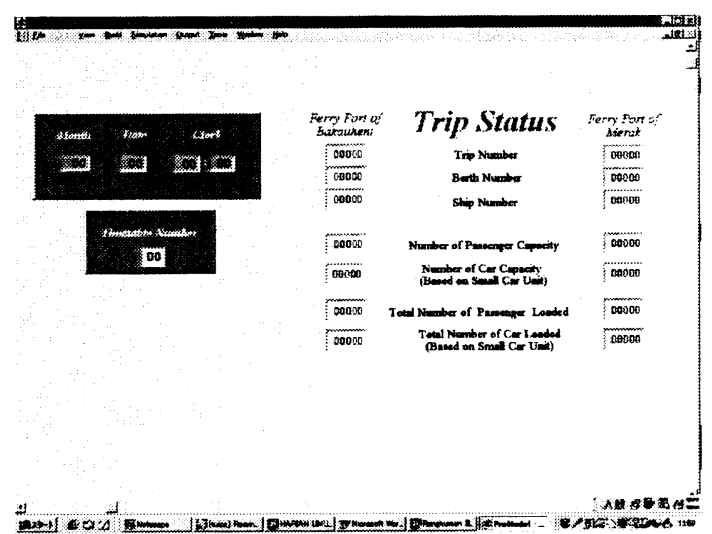

(b)

Fig.7 Typical screen-displays 


\section{Simulation Results}

\subsection{Initial experiment}

For the initial experiment, the simulation model is run during a horizon of two weeks excluding warm-up period. The warm-up period is set in two days before the starting date of the simulation.

Input parameters for arrivals in Merak and Bakauheni are given in Table 3 . In this case, it is assumed that arrivals for each day follows a normal distribution. Hourly patterns follow the patterns as shown in Fig. 3. The timetable lists of October 1998 are used to generate trips.

The simulation outputs showing the number of passengers and cars in the terminals during the first seven days in October 1998 are shown in Fig. 8(a)-(d), respectively. These figures shows the peak arrivals for passengers and cars in both Merak and Bakauheni.

Table 3 Input parameters of the arrivals

\begin{tabular}{|c|c|c|c|c|c|c|c|c|}
\hline \multirow{2}{*}{ Day } & \multicolumn{2}{|c|}{ Passengers } & \multicolumn{2}{|c|}{ Small Cars } & \multicolumn{2}{|c|}{ Buses } & \multicolumn{2}{|c|}{ Trucks } \\
\hline & Merak & Bakauheni & Merak & Bakauheni & Merak & Bakauheni & Merak & Bakauheni \\
\hline \multirow{2}{*}{ Monday } & $16,099^{2}$ & 22,271 & 1,147 & 1,018 & 292 & 310 & 1,276 & 1,277 \\
\hline & $2,269^{b}$ & 3,845 & 98 & 217 & 26 & 32 & 103 & 17 \\
\hline \multirow{2}{*}{ Tuesday } & 14,269 & 17,358 & 1,051 & 897 & 264 & 264 & 1,410 & 1,282 \\
\hline & 1,414 & 2,275 & 95 & 179 & 17 & 14 & 29 & 23 \\
\hline \multirow{2}{*}{ Wednesday } & 14,774 & 18,456 & 1,095 & 1,005 & 275 & 269 & 1,319 & 1,240 \\
\hline & 1,552 & 2,256 & 104 & 129 & 19 & 16 & 150 & 76 \\
\hline \multirow{2}{*}{ Thursday } & 15,352 & 18,309 & 1,118 & 1,017 & 293 & 278 & 1,290 & 1,260 \\
\hline & 1,696 & 2,047 & 126 & 101 & 11 & 24 & 61 & 69 \\
\hline \multirow{2}{*}{ Friday } & 16,443 & 17,789 & 1,413 & 1,118 & 292 & 276 & 1,308 & 1,161 \\
\hline & 2,500 & 1,762 & 162 & 204 & 32 & 16 & 28 & 46 \\
\hline \multirow{2}{*}{ Saturday } & 17,889 & 18,264 & 1,391 & 1,155 & 264 & 274 & 1,190 & 941 \\
\hline & 2,962 & 2,837 & 175 & 111 & 21 & 30 & 79 & 42 \\
\hline \multirow{2}{*}{ Sunday } & 17,269 & 26,191 & 1,254 & 1,495 & 301 & 298 & 668 & 1,184 \\
\hline & 1,872 & 3,748 & 146 & 176 & 22 & 25 & 43 & 53 \\
\hline
\end{tabular}

a) mean

b) standard deviation

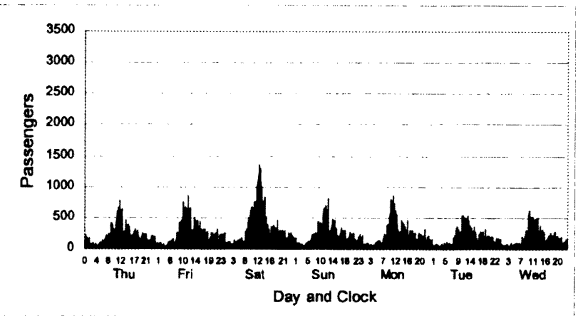

(a) Passengers in Merak

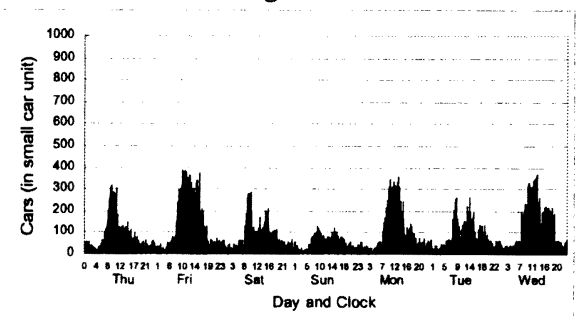

(c) Cars in Merak

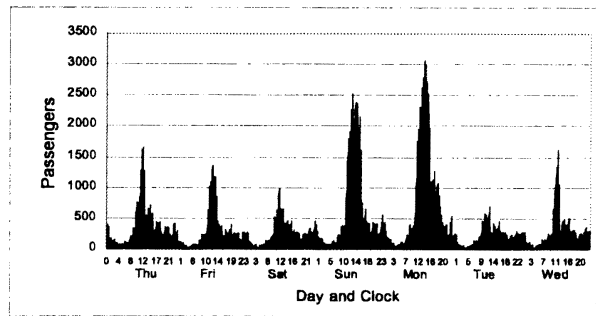

(b) Passsengers in Bakauheni

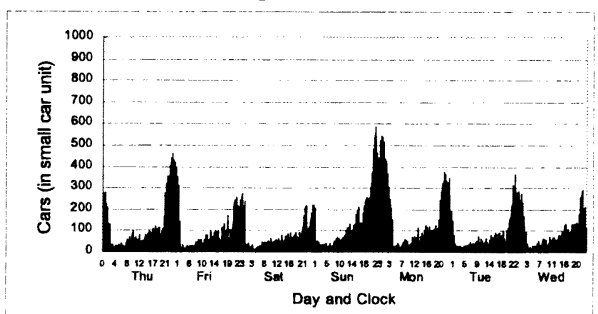

(d) Cars in Bakauheni

Fig.8 Number of passengers and cars in the terminals 


\subsection{Experiment 1}

The experiment 1 is performed to see effects of changing timetable to the waiting times. In this experiment, we change only the interdeparture time pattern of trips. Conditions such as number of trips and others are similar to the initial experiment.

In this experiment, two alternative timetables are generated. The first alternative (Timetable type 1) consists of an interdeparture time of 20 minutes between 10:00 a.m. and 18:00 p.m. and an interdeparture time of 30 minutes in the rest time. The second one (Timetable type 2) has an interdeparture time of 20 minutes (10 a.m. 1:00 a.m.), 30 minutes (7:00 a.m. $\sim 10$ a.m.), and 60 minutes (1:00 a.m. 7:00 a.m.). Fig. 9 shows the three features of the timetables including the existing one (Timetable type 0 ).

Fig. 10 shows waiting times of passengers and cars using the existing and proposed timetables. The Timetable type 2 gives the lowest of the waiting times for passengers and cars in both Merak and Bakauheni By using this alternative timetable, the waiting time of passengers in Bakauheni can be reduced about 11 minutes.

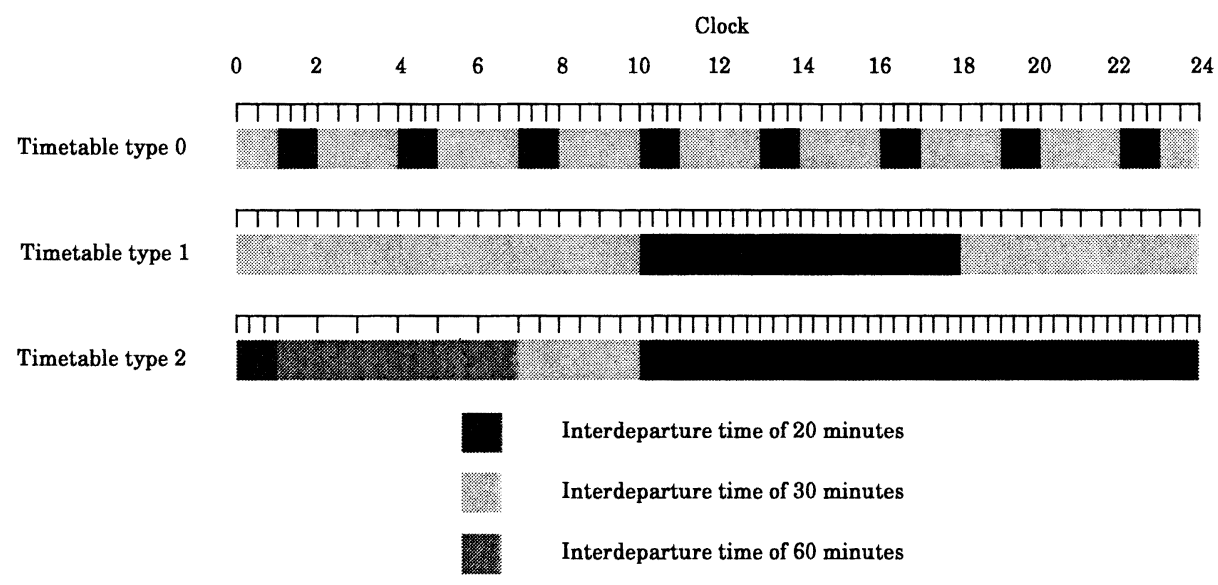

Fig.9 Features of the timetables

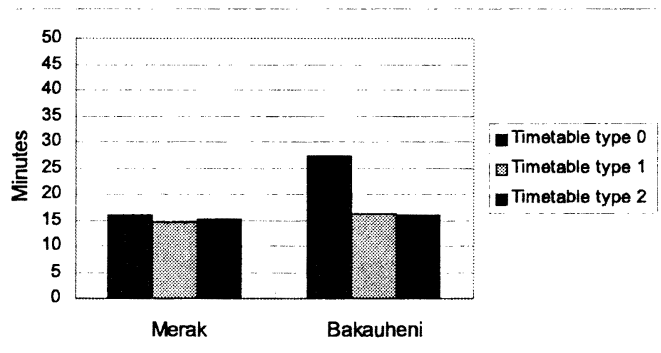

(a) Passengers

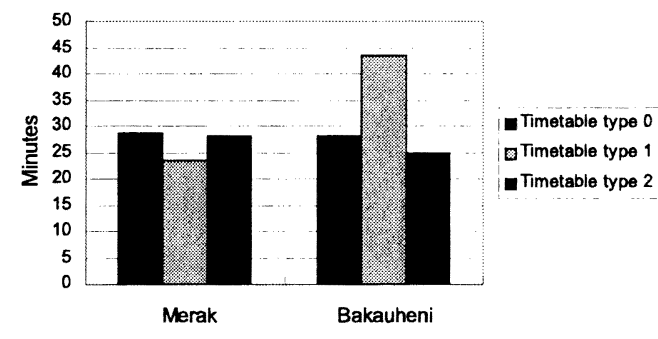

(b) Cars

Fig.10 Waiting times of passengers and cars using the existing and modified timetables 


\subsection{Experiment 2}

The experiment 2 is used to determine the most suitable ship type. It is assumed that the existing timetable is used in the experiment. The number of ships available in operation is same with the present condition.

Nine alternative ship types are generated. Each ship type has a specific size of passenger and car capacities. GRT of each ship type is estimated using a multiple linear equation derived from existing ship data $^{4)}$ where independent variables are passenger and car capacities. The cost per trip for each ship type is also estimated using a linear regression analysis from five ship data provided by Tarigan $(1992)^{1)}$ where the dependent variable is GRT. Table 4 shows data for each ship type including its capacities, GRT, and unit trip cost.

The performance of each ship type is evaluated by its total cost consisting of waiting time cost and ship running cost. The waiting time cost is calculated for both passengers and cars. For each passengers cars, the waiting cost is a product of number of passengers/cars traveled during the simulation period, average waiting time of passengers/cars in the terminal, and unit time value of passengers/cars. The unit time values are taken from OCDI's study ${ }^{6}$. The unit time value of passengers is $R p$ 7,606/day. Time values of cars are $R p$ 10,355/day for small cars, $R p$ $54,548 /$ day for buses, and $\mathrm{Rp} 27,289$ /day for trucks.

The ship running cost is calculated as a product of total trips during the simulation period and cost per trip. This ship running cost includes the total trip cost using twenty ships available.

The total cost per day is given in Fig. 11. Note that ship type 0 relates with the existing condition of ship and ship type 1-9 correspond to the each ship type as listed in Table 4. In this case, ship type 1 gives the lowest total cost and it is better compared with the existing condition. From this figure, it can be seen that the total cost is greatly affected by ship running cost. Compared with the ship running costs, the waiting time costs are very low. These are caused by the lowness of the unit time value. As a comparison, the unit time value of passengers in Japan is US $\$ 30,971$ per year ${ }^{7)}$ or estimated around $R p$ 678,816 per day (assuming that US $\$ 1=R p 8,000$ ). This value is almost 89 times compared with the Indonesian unit time value.

Table 4 Data for each alternative ship types

\begin{tabular}{|c|c|c|c|c|c|}
\hline \multirow[b]{2}{*}{$\begin{array}{l}\text { Ship } \\
\text { type }\end{array}$} & \multirow[b]{2}{*}{ Passenger capacity } & \multicolumn{2}{|c|}{ Car capacity } & \multirow[b]{2}{*}{ Estimated GRT } & \multirow[b]{2}{*}{$\begin{array}{l}\text { Estimated cost per } \\
\text { trip (million rupiahs) }\end{array}$} \\
\hline & & $\begin{array}{l}\text { Mixed car } \\
\text { unit }^{2}\end{array}$ & Small car unit & & \\
\hline 1 & 600 & 80 & 116 & 4,030 & 1.144 \\
\hline 2 & 600 & 90 & 131 & 4,353 & 1.236 \\
\hline 3 & 600 & 100 & 145 & 4,676 & 1.328 \\
\hline 4 & 700 & 80 & 116 & 4,211 & 1.196 \\
\hline 5 & 700 & 90 & 131 & 4,534 & 1.287 \\
\hline 6 & 700 & 100 & 145 & 4,857 & 1.379 \\
\hline 7 & 800 & 80 & 116 & 4,392 & 1.247 \\
\hline 8 & 800 & 90 & 131 & 4,715 & 1.339 \\
\hline 9 & 800 & 100 & 145 & 5,038 & 1.430 \\
\hline
\end{tabular}

4) Small car $=55 \%$, buses and trucks $=45 \%$

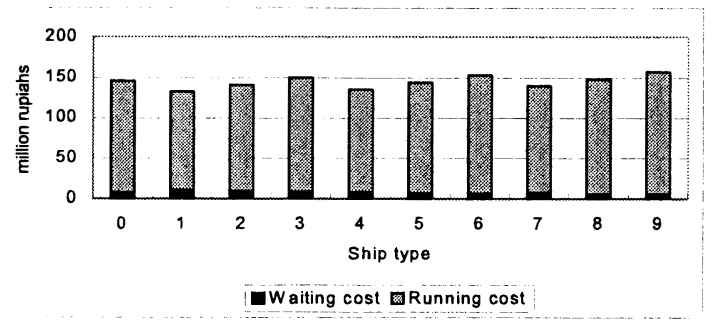

Fig.11 Total cost per day of the system 


\section{Conclusions}

In this paper a simulation model for the ferry transportation system has been presented. The simulation model is developed for the MerakBakauheni ferry route, Indonesia. The model developed considers the hourly arrival patterns of passengers and cars.

In addition to initial experiment, two types of experiments are carried out. The first experiment involve changing timetables. The second one is to determine the most suitable ship type in terms of passenger and car capacities.

One of advantages of the simulation model is the capability to handle a complex system with the existence of the dynamic nature and random events. In this paper, the simulation model is used to analyze some operation designs. By using the simulation model, alternative operation designs can be analyzed and the most suitable designs can be proposed to give a better performance of the system.

\section{Acknowledgment}

This work is further development of the previous work sponsored by Japan Society Promotion for the Promotion of Sciences (JSPS). The authors express thanks to Prof. Kuniji Kose (Hiroshima University), the head of Asian Cooperation Program, Marine Transportation Engineering, JSPS, for the supports.
The authors also express thanks to the Chairman of Public Relation Affairs in the Directorate General of Land Transportation, Ministry of Communication, the Republic of Indonesia, and staffs of PT. ASDP, Indonesia, in the Head Office, Merak Branch, and Bakauheni Branch for providing useful data and information.

\section{References}

1) Tarigan, Perlindungan: Operational Evaluation of the Merak-Bakauheni Ferry Route using a Simulation Technique, Master Thesis, Graduate Program of Transportation, Bandung Institute of Technology, 1992

2) Suprayogi: Simulation of Ferry Transportation Systems, Report on the Visit of Japanese Researches to Indonesia in August 1999, Report No.99-1, October 30, 1999. pp. 339-351

3) Directorate General of Land Transportation, Ministry of Communication, the Republic of Indonesia: Development of ASDP's Facilities, 1998.

4) PT. ASDP, Merak Branch: Operated Ships and Their Capacities, 1998

5) PT. ASDP, Merak Branch: Ro-ro ships timetable of Merak-Bakauheni Ferry Route, 1998

6) The Overseas Coastal Area Development Institute of Japan (OCDI): Final Report, The Development Study on the Nationwide Ferry Service Routes (Stage II) in the Republic of Indonesia, March 1999

7) Japan Information Network: http//jinjapan.org 